\section{Putting science in its place}

\section{David Dickson talks to Joao Frank da Costa, secretary-general of the United Nations Conference on Science and Technology}

A

RECENT background document to next year's United Nations Conference on Science and Technology for Development, to take place in Vienna, opens with the blunt words: "The actual substance of science and technology will not be under discussion at UNCSTD,"

The directness of the approach-as well as the sentiments behind it-has ruffled quite a few feathers in the international scientific community. However, it has left few in doubt of the views of the conference's secretarygeneral, Mr Joao Frank da Costa.

An economist and lawyer by training, with almost thirty years' experience in the Brazilian diplomatic service, $\mathrm{Mr}$ da Costa is no stranger to the United Nations scene, having frequently represented his country at sessions of the General Assembly. Nor is he a stranger to science policy issues. While serving at UNESCO he was secretary-general of the conference for the establishment of a Latin American Centre of Physics. More recently he has served twice as chairman of the UN Committee on Science and Technology for Development.

However, the scheme that he has helped to set up for UNCSTD reveals an approach that is significantly different from "science and development" type conferences of the past, which have tended to gather heterogeneous groups of experts to focus on particular issues of international concern.

$\mathrm{Mr}$ da Costa characterises this as a "top down" approach, producing impressive-looking plans of action, but all too often isolated from the mechanisms of social and economic change. In contrast, UNCSTD is being planned on a "bottom up" direction, confronting directly the complex social, economic and political entanglements of the real world.

$\mathrm{Mr}$ da Costa relates this to a new way of looking at science and its role in development, a role related to the philosophy of the New International Economic Order. "The traditional view of science as universally-available knowledge is no longer realistic, especially when the positive effects of science and technology are felt in some countries and not in others," he says. More realistic, but still with its limitations, is the approach which treats knowledge as a commodity and concentrates on attempts to facilitate the international flow of science and technology.

"The third view, and the one that will be stressed at UNCSTD, is that science and technology are not really commodities, but are the product of social and political processes", $\mathrm{Mr}$ da Costa says. Related to this, he suggests the need for a new approach to science policy.

"The first attempts to develop science policies for the developing countries tended to produce abstract plans that floated in the air, not obeying any particular concept of development." Subsequently there was a shift to attempts to insert science directly into plans for economic development, with progress being measured essentially by economic parameters, such as the percentage of gross national product being devoted to research and development.

"The step which it is now necessary to take is to integrate science and technology into broad development objectives, not only concentrating on their economic aspects but on their social, political and cultural implications as well."

The agenda for UNCSTD reflects this approach, tackling problems in what $\mathrm{Mr}$ da Costa calls a "horizontal" manner with topics, each essentially social or economic in nature, grouped according to the way that they impede or promote the applications of science and technology to development problems.

Shifting the emphasis in this way has not been without its critics. Some have claimed that, as a result, the conference will not really be about science at all-or even about real-world problems but fear that it could degenerate into a morass of bureaucratic haggling. Others fear that, by dealing only with government-sanctioned positions, the value of any outcome will be severely limited.

$\mathrm{Mr}$ da Costa expresses concern-although not necessarily agreement-. with both these positions. For example, even within a strict development perspective, he claimed that there still exists a role for basic science in the developing countries "not necessarily for its own sake, but because it provides a good training for skilled manpower, and in this and other ways will reduce dependency on the developed countries."

As to political restrictions, he argues -in line with recent policies of the Brazilian government that development cannot be left to market forces, but that "whether or not it is desirable, the state is nowadays the only entity

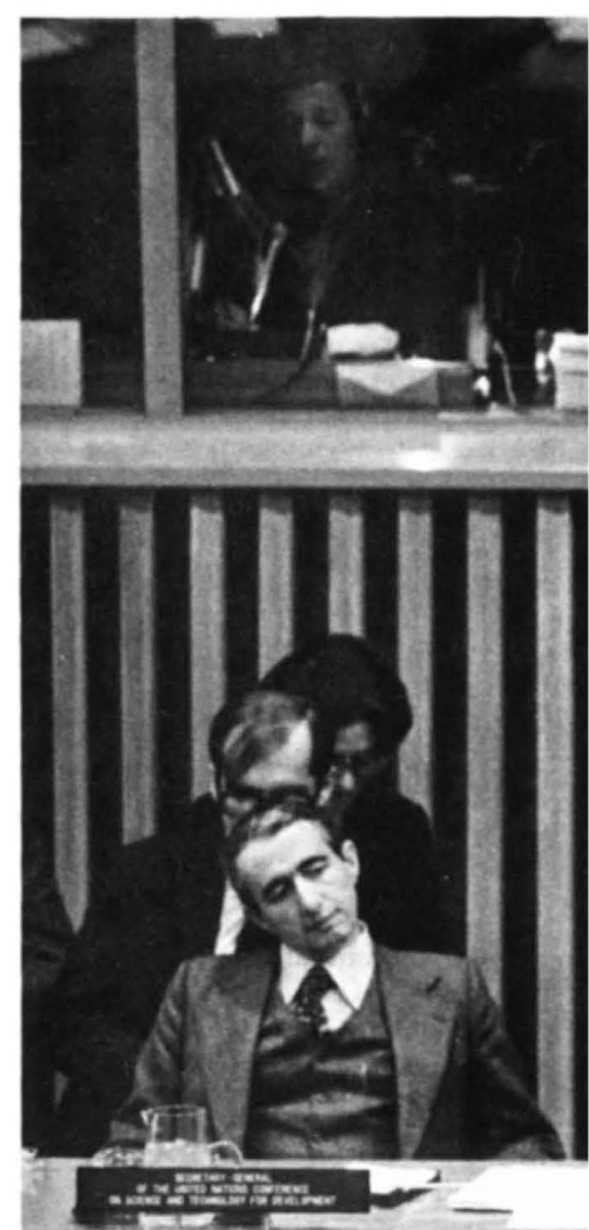

da Costa: translating science into a broader context

having the capacity and the necessary approach to take responsibility for the well-being of society."

In arguing that science and technology must always be seen as part of a broad social and political environment, $\mathrm{Mr}$ da Costa admits to sharing some of the concerns of those who, in recent years, have drawn attention to the costs, as well as the benefits, of science-based industrial progress.

"This popular reaction has been useful in developing a new perspective on science and technology, even though at times it may have been more emotional than informed. And whether the traditional western vision of science remains universally appropriate may well be an important topic of discussion at UNCSTD."

On one theme, $\mathrm{Mr}$ da Costa is in agreement with the critics of science, namely that scientists should no longer be treated as if they stood on pedestals, nor considered experts in development problems outside their own speciality. "The sight of a Nobel prizewinner signing a manifesto does not fool anyone any more," he says.

Where scientists should get involved in UNCSTD preparation, he suggests, 
is in encouraging a three-way dialogue between governments, the public and themselves, and concentrating their efforts on the national papers. But as he told a recent meeting of the American Association for the Advancement of Science, "scientists sometimes find it difficult to accept that the actual application of knowledge to the problems of society depends on a decision-making process normally situated at the government level."

\section{Soviets climb down on mental hospital detentions}

Sovier misuse of psychiatry as a means of political repression may be decreasing, according to Mrs Sofiya Kallistratova, a retired Moscow lawyer. Mrs Kallistratova, who in 1970 had defended General Petr Grigorenko, one of the most famous of the 'psychiatric dissidents' said recently that the forced hospitalisation of dissidents as being mentally ill was now being phased out in the major cities and in cases when the dissident in question was well-known. This change of policy, she explained, was the result of the protest campaign which has been waged incessantly over the last few years.

Within the Soviet Union, such protest is headed by the dissident "Working Commission for the Investigation of the Use of Psychiatry for Political Purposes', whose membership is said to include two psychiatrists who so far have remained anonymous. Since its foundation in autumn 1976, the 'Commission' has circulated a samizdat bulletin, listing cases of psychiatric repression; the latest issue (No. 9) of which also notes the arrest of Aleksandr Podrabinek, a member of the Commission.

Podrabinek is charged under Article 191 -of the Soviet Constitution, with having maliciously circulated libellous fabrications harmful to the Soviet state. The main 'evidence' against him is his authorship of a 265-page semizdat document Punitive Medicine, dealing with political abuses of psychiatry. (Podrabinek was, until his arrest, a paramedic working with an emergency ambulance unit, a means of conveyance often used for the hospitalisation of dissidents).

Under Soviet law, proof that the allegations contained in the document are true or were published in good faith would constitute a complete defence. Since the history of recent trials under Article 191 suggests that such proof would not be permitted to bc offered in court, a 'hearing' was called in London last week, to compile a dossier of defence evidence to be forwarded to the Soviet court and to be made available to relevant human rights organisations abroad.

The hearing, conducted by $\mathrm{Mr}$ Louis Blom-Cooper, Q.C. at the Institute of Advanced Legal Studies, called as 'witnesses' (either in person or via taped interviews) a number of pro- minent ex-dissidents-Vladimir Bukovskii, who first drew world attention to the problem of psychiatric abuse, Dr Marina Volkhanskaya, who refused to administer neuroleptic drugs to political 'cases', Leonid Plyushch and General Grigorenko, former victims of the abuses.

A less familiar figure at the hearing was Dr Yurii Novikov, a psychiatrist, recently arrived in the West, who formerly worked at the Serbskii Institute of Forensic Psychiatry, a body which exercises overall control of all forensic psychiatry in the Soviet Union. Dr Novikov made no claims to heroism, stating, for example, that when

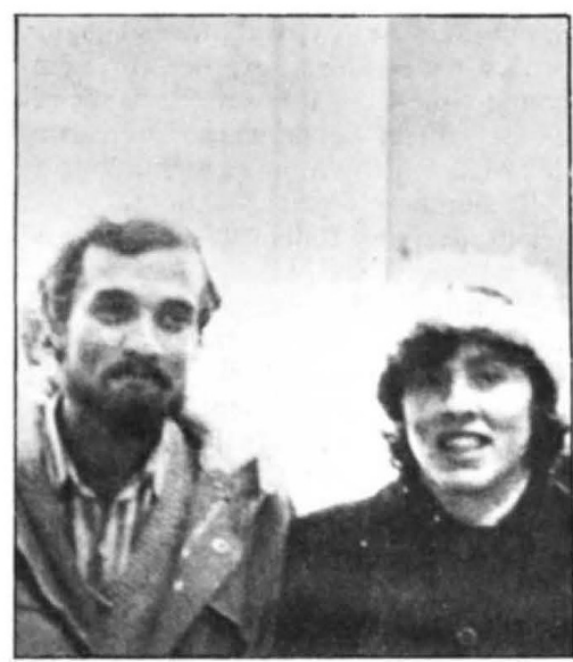

Podrabinek, now under arrest, and fellow dissident Irina Kaplun

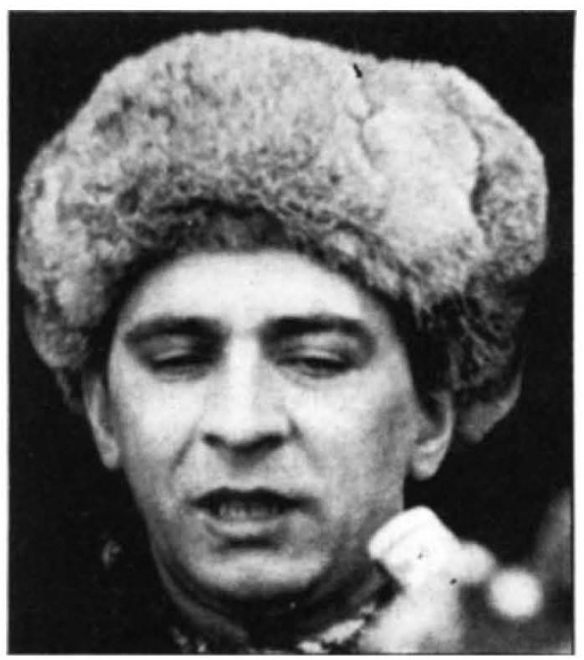

Leonid Plyuschch, speaking in Austria shortly after release from a Soviet mental hospital pressurised by a KGB official to certify a prisoner in a labour camp who was "making a nuisance of himself", he slid out of an awkward situation by suggesting that this was too complicated a case for him to decide, and recommended that the man be sent to the Serbskii Institute for a second opinion.

Perhaps because he makes no such claims for himself Dr Novikov's evidence is all the more credible. Certainly his 'inside' picture of Soviet forensic psychiatry is a frightening one. He asserts, for example, that one of the Assistant Ministers of Health, Evgenii S. Kuritsyn, who deals only with psychiatric matters, is a member of the KGB. He also gave a vivid account of the activity of Dr Georgii Morozov, a leading psychiatrist at the Serbskii Institute, to forestall criticism of Soviet psychiatry at the 1977 World Psychiatric Association Congressnotably by soliciting support from psychiatrists of the socialist bloc and from Finland.

Novikov's description of the Soviet pre-Honolulu campaign makes an ironic contrast to recent developments within the World Psychiatric Association. One of the results of Honolulu was the establishment of a committee to look into issues of professional ethics. Although the machinery for investigating such matters is still being worked out, there are suggestions that the committee might be set up in such a way that it is, by definition, totally ineffective. One informed source indicated to Nature that the WPA committee will not investigate any individual complaint of abuse; all such matters must be presented via the relevant national delegation. If implemented, such a situation would be worthy of Gilbert. A latterday PoohBah would appear before the Committee as both appellant (on behalf of the individual making the complaint) and defendant (on behalf of his country's psychiatric profession). One can only hope that this is a misreading of the situation, and that the WPA will adopt an Amnesty-like situation, where national delegations present complaints of abuse relating to countries other than their own. In the meantime, the Royal College of Psychiatrists is to set up its own body to study such complaints wherever they occur.

Vera Rich 